Gut, 1980, 21, 1093-1096

Case report

\title{
Perforation of an adenocarcinoma of the small bowel affected by regional enteritis
}

\author{
JENNY HEATHCOTE, C M KNAUER,* D OAKES, AND R W R ARCHIBALD \\ From Departments of Medicine (Division of Gastroenterology), Surgery and Pathology, Santa Clara \\ Valley Medical Center, San Jose, California, USA
}

SUMMARY This report is of a patient with long-term small bowel regional enteritis who presented with a perforation of an adenocarcinoma involving a diseased portion of ileum. Adenocarcinoma of the small bowel is rare. The incidence of small bowel adenocarcinoma may be higher in patients with regional enteritis, but a definite relationship cannot be established on the basis of data presently available. Small bowel adenocarcinoma in regional enteritis usually presents with obstructive symptoms.

Perforation of the small bowel affected by regional enteritis is infrequently seen, as is adenocarcinoma of the small bowel. ${ }^{1-3}$ We wish to describe the case of a woman with chronic regional enteritis who became acutely ill and was found to have a perforation through an adenocarcinoma in an area of ileum affected by regional enteritis.

\section{Case report}

(HL no. 7-29-40-02) This 33 year old woman was admitted on 31 August 1978 with an acute abdomen. She first presented in October 1969 with diarrhoea and mid-abdominal cramping of $2 \frac{1}{2}$ years duration. The diarrhoea occurred four or five times a day, was watery, occasionally nocturnal, with cramping but without mucus, pus, or blood. At that time she had moderate muscle wasting, clubbing and marked pitting oedema to the knees. Proctoscopic examination was normal. The diagnosis of regional enteritis was made on the basis of her history, physical examination, and radiological examination. There was no large bowel involvement as judged by barium enema. She was managed on sulphasalazine $1 \mathrm{~g}$ qid, ferrous sulphate, and bi-monthly vitamin $B_{12}$ injections. She did well with a weight

*Address for correspondence and reprint requests: C Michael Knauer, MD, Santa Clara Valley Medical Center, Division of Gastroenterology, 751 South Bascom Avenue, San Jose, California 95128, (408) 279-5683, USA.

Received for publication 18 April 1980 gain of $6 \cdot 3 \mathrm{~kg}(14 \mathrm{lb})$, loss of oedema, and disappearance of cramping and diarrhoea.

She continued to do well on this regimen until January 1978 when she developed postprandial and nocturnal epigastric burning, partially controlled by antacids. Subsequently she noted mid-back, periumbilical, and lower abdominal pain. When seen in late March 1978 she had a tender periumbilical abdominal mass and $x$-ray studies again showed extensive regional enteritis. There was no evidence of duodenal ulcer disease. Prednisone $30 \mathrm{mg}$ per day was started, resulting in rapid improvement of her symptoms and gradual disappearance of the mass. By June 1978 prednisone dosage was $15 \mathrm{mg}$ daily, she occasionally felt bloated, still had some backache, but otherwise was doing well.

Her admission on 31 August 1978 was heralded by a 'flu-like' syndrome consisting of abdominal pain and backache, and fever with chills of 36 hours' duration. Three hours before admission, she experienced sudden lower abdominal pain and syncope. Her pain increased and on admission she was found to have signs of peritoneal irritation and radiographic evidence of free air in the abdomen. At operation a perforation in an area of midileal regional enteritis was found. The most diseased portions of bowel on either side of the perforation were removed, and a primary end-to-end anastomosis accomplished.

The resected portion of small bowel, $87 \mathrm{~cm}$ in length, showed typical gross and microscopical 
features of regional enteritis, with narrowing of the lumen and thickening of the bowel wall by transmural inflammation. The mucosa was extensively ulcerated, with intervening polypoid projections of residual intact mucosa. Other microscopic features relating to regional enteritis included lymphangiectasia and oedema of the submucosa and epithelioid granulomata containing laminated Schaumann bodies (Fig. 1).

Near the mid-portion of the resected specimen there was a $4.5 \mathrm{~cm}$ segment of bowel which showed even greater mural thickening. A perforation could be demonstrated through this region and was accompanied by a creamy serosal exudate. Microscopically this portion showed a rather poorly differentiated adenocarcinoma extending through the bowel wall into mesenteric fat. The tumour formed abortive acinar structures and cytoplasmic mucin could be demonstrated by appropriate stains (Fig. 2). None of the 21 lymph nodes identified showed metastatic carcinoma, though several contained granulomata.

On the eighth postoperative day the patient had an upper gastrointestinal haemorrhage. She required
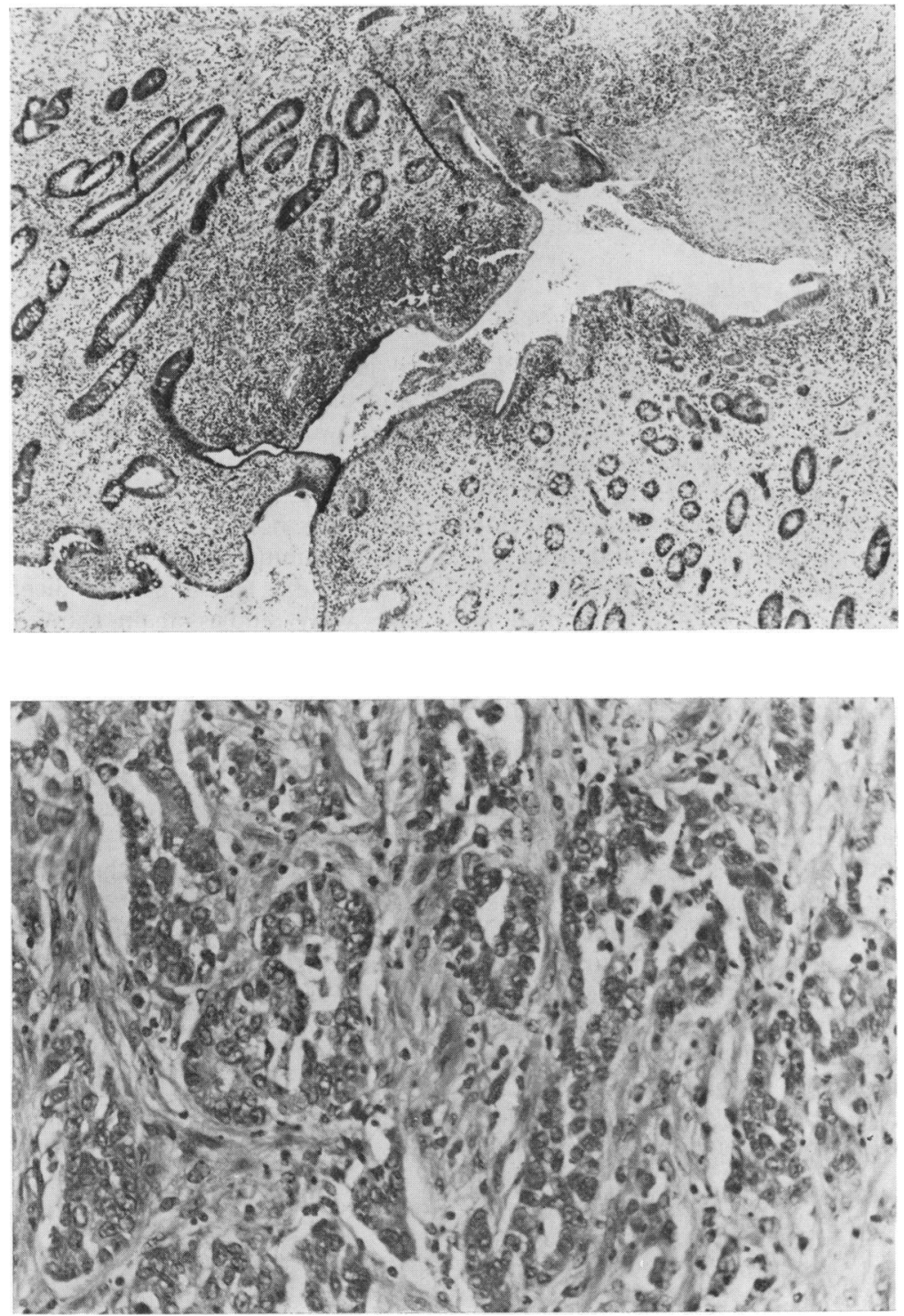

Fig. 1 Mucosal ulceration typical of Crohn's disease, with submucosal oedema and heavy inflammation. $H$ and $E, \times 62$.

Fig. 2 Adenocarcinoma infiltrating the muscularis propria of the ileum. Cellular pleomorphism and abortive gland formation are evident. $H$ and $E$, $\times 200$. 
five units of packed cells and at endoscopy was found to have multiple stress ulcerations of the stomach. She subsequently did well and was discharged on the 13th postoperative day.

In January 1979 she was readmitted with a partial small bowel obstruction which cleared with non-operative therapy. A subsequent radiograph of the small bowel was completely normal. When seen in February 1980, one and one-half years after the perforation, she had no symptoms, had regained her weight, and had resumed all her prior activities. Her laboratory studies were also normal including a carcinoembryonic antigen determination.

\section{Discussion}

Crohn in his review of regional enteritis in $1958^{1}$ remarked that acute, frank perforation never occurs. Nevertheless, Kyle ${ }^{4}$ reviewed 91 such cases of perforation and added four of his own. In 1972 Menguy $^{5}$ reported on six patients with free perforations and reviewed 40 others, all with clear descriptions of perforations and peritonitis at operation. He noted poor results in those who had simple suture plication of the perforation $(45 \%$ mortality and $25 \%$ serious postoperative complications) with considerably better results in those who had resection and primary anastomosis (15\% mortality and $15 \%$ serious complications). His six patients were treated with resection and exteriorisation of the bowel ends-with no mortality and only one serious complication. He advocated this approach for all cases of perforation of the small bowel in patients with regional enteritis. While this less aggressive operation has much to recommend it, cases in which the interval between perforation and operation is short-as in our patient-may sometimes be safely managed by resection and primary anastomosis.

Adenocarcinoma of the small bowel is an uncommon disease with an incidence of approximately $0 \cdot 3$ per 100000 population per year. ${ }^{6}$ To date, 40 cases of primary adenocarcinoma of the small bowel have been reported in patients with regional enteritis. ${ }^{7-18}$ In follow-up studies of patients with enteritis the incidence of primary small bowel adenocarcinoma is one per 354 cases. ${ }^{17}$ These data suggest a greater incidence of primary small bowel carcinoma in regional enteritis than in normal small bowel; however, the studies to date are still inadequate.

For small bowel carcinoma in regional enteritis to present as a perforation, as in this case, is unique. The majority of patients with carcinoma and regional enteritis have presented with obstructive symptoms generally on a background of long-term disease. ${ }^{7-15}$ Peritonitis in such a situation has been reported but the perforations have been through inflammatory tissue, not through the tumour. When perforations do occur in areas of regional enteritis they are usually sealed off by the surrounding tissues and rarely result in pneumoperitoneum. ${ }^{15-16}$ In several reports malignant tumour was found in a bypassed loop of diseased small bowel. ${ }^{1011} 1415$

Adenocarcinoma has also been found in association with fistulous tracts arising from regional enteritis. ${ }^{71}$ Most malignant tumours of the small bowel are found in the jejunum. The malignant tumours found in association with regional enteritis are usually in the ileum and nearly always present in a much younger age group. When regional enteritis is complicated by adenocarcinoma, dysplasia and multiple tumour sites may be seen. ${ }^{10}{ }^{18}$ Nevertheless, studies correlating dysplasia with neoplasms in regional enteritis, such as done by Morson in ulcerative colitis, ${ }^{19}$ have not been reported. With our patient, like most of the reported cases of adenocarcinoma in regional enteritis, the diagnosis was not suspected either preoperatively or at the time of operation. Frequently the tumour is missed macroscopically ${ }^{18}$ and hence the full significance of the disease is recognised only during the postoperative period. Although obstructive symptoms appear to be the most frequent indication for surgery, the adenocarcinoma is almost never the cause of the obstruction. These tumours are usually found incidentally and indicate the need for careful examination of the entire small bowel. The survival of subjects with primary malignant tumours of the small bowel in the absence of regional enteritis is low $(20-30 \%))^{2}{ }^{3}$ No five year survivors are recorded in small bowel adenocarcinoma associated with regional enteritis. ${ }^{13}$ It is not surprising that the survival of these patients is so dismal, because of delayed diagnosis in the clinical setting of recurrent symptomatic episodes.

\section{References}

${ }^{1}$ Crohn BB, Yarnis H. Regional enteritis. New York: 1958: 71.

${ }^{2}$ Colcock BP, Adamson NE Jr. Adenocarcinoma of the jejunum and ileum. Surg Clin N Amer 1959; 39: 737. ${ }^{3}$ Hancock RJ. An eleven year review of primary tumors of the small bowel including the duodenum. Canad Med Assoc J 1970; 103: 1177-9.

${ }^{4}$ Kyle J, Caridis T, Duncan T, Ewen SWB. Free perforation in regional enteritis. Am J Dig Dis 1968; 13: 275-283.

${ }^{5}$ Menguy R. Surgical management of free perforation of the small intestine complicating regional enteritis. Ann Surg 1972; 175: 178-189. 
${ }^{6}$ Darke SG, Parks AG, Grogono JL, Pollock DJ. Adenocarcinoma and Crohn's disease. Br J Surg 1973; 60: $169-75$.

${ }^{7}$ Lightdale CJ, Sternberg SS, Posner G, Sherlock P. Carcinoma complicating Crohn's disease. $\mathrm{Am} \mathrm{J}$ Med 1975; 59: 262-8.

${ }^{8}$ Ginzberg L, Schneider KM, Dreizin DH. Carcinoma of the jejunum occurring in a case of regional enteritis. Surg 1956; 39: 347-51.

${ }^{9}$ Morowitz DA, Block GE, Kirsner JB. Adenocarcinoma of the ileum complicating chronic regional enteritis. Gastroenterology 1968; 55: 397-402.

${ }^{10}$ Tyers GFO, Steiger E, Dudrick SJ. Adenocarcinoma of the small intestine and other malignant tumors complicating regional enteritis. Ann Surg 1969; 169: 510-8.

${ }^{11}$ Schuman BM. Adenocarcinoma arising in an excluded loop of ileum. $N$ Engl J Med 1970; 283: 136-7.

${ }^{12}$ Rha CK, Klein NC, Wilson JM Jr. Adenocarcinoma of the ileum with coexisting regional enteritis. Arch Surg 1971; 102: 630-3.

${ }^{13}$ Papp JR, Pollard HM. Adenocarcinoma occurring in
Crohn's disease of the small intestine. Am J Gastroenterol 1971; 56: 149-56.

${ }^{14}$ Frank JD, Shorey BA. Adenocarcinoma of the small bowel as a complication of Crohn's disease. Gut 1973; 14: 120-4.

${ }^{15}$ Hoffert PW, Wengarten B, Friedman LD, Morecki R. Adenocarcinoma of the terminal ileum in a segment of bowel with coexisting active ileitis. NY State J Med 1963; 63: 1567-71.

${ }^{16}$ Cantwell JD, Kettering RF, Carney JA. Adenocarcinoma complicating regional enteritis: report of a case and review of the literature. Gastroenterology 1968; 54: 599-604.

${ }^{17}$ Wyatt AP. Regional enteritis leading to carcinoma of the small bowel. Gut 1969; 10: 924-7.

${ }^{18}$ Fleming KA, Pollock AC. A case of 'Crohn's carcinoma'. Gut 1975; 16: 533.

${ }^{19}$ Lennard-Jones JE, Morson BC, Ritchie JK, Shove DC, Williams CB. Cancer in colitis: assessment of the individual risk by clinical and histological criteria. Gastroenterology 1977; 73: 1280-9. 